\title{
The hybrid procedure for hypoplastic left heart syndrome: A procedure still looking for its place
}

\author{
Carlos M. Mery, MD, MPH
}

\footnotetext{
From the Division of Congenital Heart Surgery, Michael E. DeBakey Department of Surgery, Texas Children's Hospital/Baylor College of Medicine, Houston, Tex.

Disclosures: Author has nothing to disclose with regard to commercial support.

Received for publication Aug 24, 2016; accepted for publication Aug 26, 2016; available ahead of print Sept 23, 2016.

Address for reprints: Carlos M. Mery, MD, MPH, Division of Congenital Heart Surgery, Texas Children's Hospital, 6621 Fannin St - MC19345H, Houston, TX 77030 (E-mail: cmmery @ texaschildrens.org).

J Thorac Cardiovasc Surg 2017;153:173-4

$0022-5223 / \$ 36.00$

Copyright (c) 2016 by The American Association for Thoracic Surgery

http://dx.doi.org/10.1016/j.jtcvs.2016.08.053
}

Despite significant improvements in the management of hypoplastic left heart syndrome, mid- and long-term results remain suboptimal. During the last 15 years, the hybrid procedure (pulmonary artery banding, maintaining ductal patency with stenting or prostaglandin, and atrial septostomy, Figure 1) has emerged as an alternative to the Norwood procedure in an effort to improve outcomes by delaying full surgical reconstruction. ${ }^{1}$ Despite initial enthusiasm for this approach, ${ }^{2,3}$ both the value of this strategy and the population in which it may provide a significant benefit remain unclear.

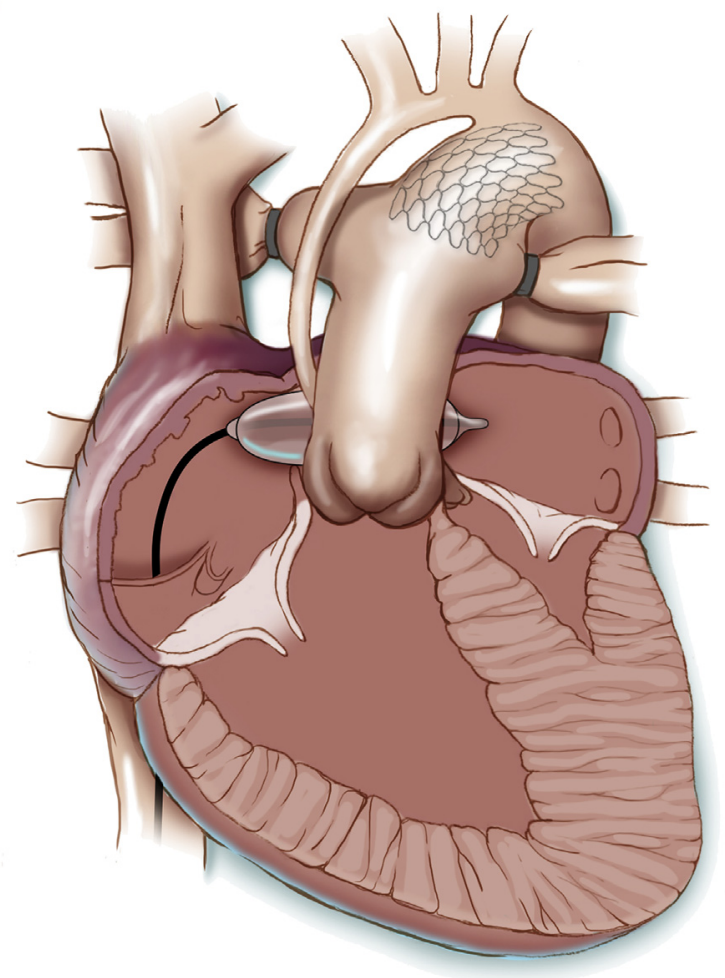

FIGURE 1. Hybrid approach for hypoplastic left heart syndrome including placement of bilateral pulmonary artery bands, ductal stent, and balloon atrial septostomy. (C) 2016 Texas Children's Hospital (reprinted with permission). was small.

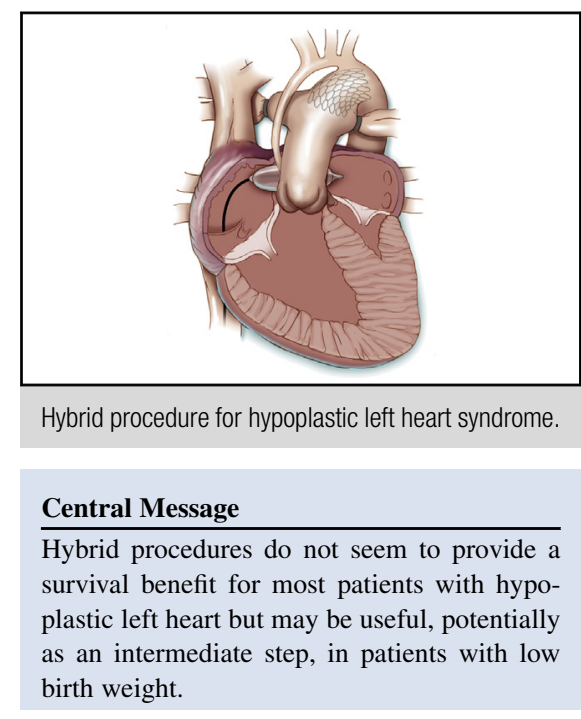

See Article page 163.

In the current issue of the Journal, Wilder and colleagues ${ }^{4}$ describe a prospective observational cohort study that compares 3 management strategies: Norwood with a modified Blalock-Taussig shunt (NW-BT), Norwood with a right ventricle to pulmonary artery conduit (NW-RVPA), and the hybrid procedure. To account for confounding factors, they used 2 strategies: a sophisticated multivariable survival analysis in which they used the entire cohort and the creation of separate propensity matched groups to compare hybrid patients with each of the other 2 groups. They concluded that patients with NW-RVPA had overall better survival than those with NW-BT and hybrid procedures (which had similar survival). It is likely that the survival advantage seen for NW-RVPA over the other 2 strategies is related to improved coronary and systemic perfusion, because both NW-BT and hybrid procedures yield similar physiological states with significant diastolic runoff.

Not surprisingly, low birth weight $(<2.5 \mathrm{~kg})$ was an important risk factor for death; however, hybrid procedures seemed to mitigate this increase in risk compared with patients undergoing a Norwood procedure. In particular, hybrid procedures offered a modest survival advantage in patients $<2 \mathrm{~kg}$ compared with NW-RVPA and $<3 \mathrm{~kg}$ compared with NW-BT. Although this conclusion seems to be accurate, the number of patients in each strategy (in particular the Norwood) at the low end of birth weight 
An important limitation of this analysis is the heterogeneity of procedures by center. Of the 20 centers, only 11 performed any hybrid procedures, and 1 center accounted for $42 \%$ of all hybrid procedures performed. Because centers may be associated with other possibly unaccounted risk factors and different learning curves, the conclusions may not be easily generalizable.

An interesting observation is that $24 \%$ of patients who initially underwent a hybrid procedure were then converted to a Norwood. No additional data are provided on these patients, but one could envision using an initial hybrid approach in certain high-risk patients with later conversion to a Norwood once the conditions, such as weight, become more favorable.

It is becoming clear that different patients may benefit from different approaches. Hybrid procedures do not seem to provide an overall survival advantage for most patients. However, patients with low birth weight may benefit from at least an intermediate hybrid strategy. We seem to be getting closer to the ultimate goal of being able to offer each individual patient the management strategy that will lead to the best possible outcome, not only for quantity, but also for quality of life.

\section{References}

1. Akintuerk H, Michel-Behnke I, Valeske K, Mueller M, Thul J, Bauer J, et al. Stenting of the arterial duct and banding of the pulmonary arteries: basis for combined Norwood stage I and II repair in hypoplastic left heart. Circulation. 2002;105: 1099-103.

2. Bacha EA, Daves S, Hardin J, Abdulla RI, Anderson J, Kahana M, et al. Singleventricle palliation for high-risk neonates: the emergence of an alternative hybrid stage I strategy. J Thorac Cardiovasc Surg. 2006;131:163-71.

3. Galantowicz M, Cheatham JP, Phillips A, Cua CL, Hoffman TM, Hill SL, et al. Hybrid approach for hypoplastic left heart syndrome: intermediate results after the learning curve. Ann Thorac Surg. 2008;85:2063-70.

4. Wilder TJ, McCrindle BW, Hickey EJ, Ziemer G, Tchervenkov CI, Jacobs ML, et al. Is a hybrid strategy a lower-risk alternative to stage-1 Norwood operation? J Thoracic Cardiovasc Surg. 2017;153:163-72.e6. 